\title{
Surface Properties of Al-Fe-Si Liquid Alloy Using Thermodynamic Database
}

\author{
U. Mehta, S. K. Yadav, I. Koirala, D. Adhikari
}

\section{Journal of Nepal Physical Society}

Volume 6, Issue 2, December 2020

ISSN: 2392-473X (Print), 2738-9537 (Online)

\section{Editors:}

Dr. Binod Adhikari

Dr. Bhawani Joshi

Dr. Manoj Kumar Yadav

Dr. Krishna Rai

Dr. Rajendra Prasad Adhikari

Mr. Kiran Pudasainee

JNPS, 6 (2), 10-19 (2020)

DOI: http://doi.org/10.3126/jnphyssoc.v6i2.34849

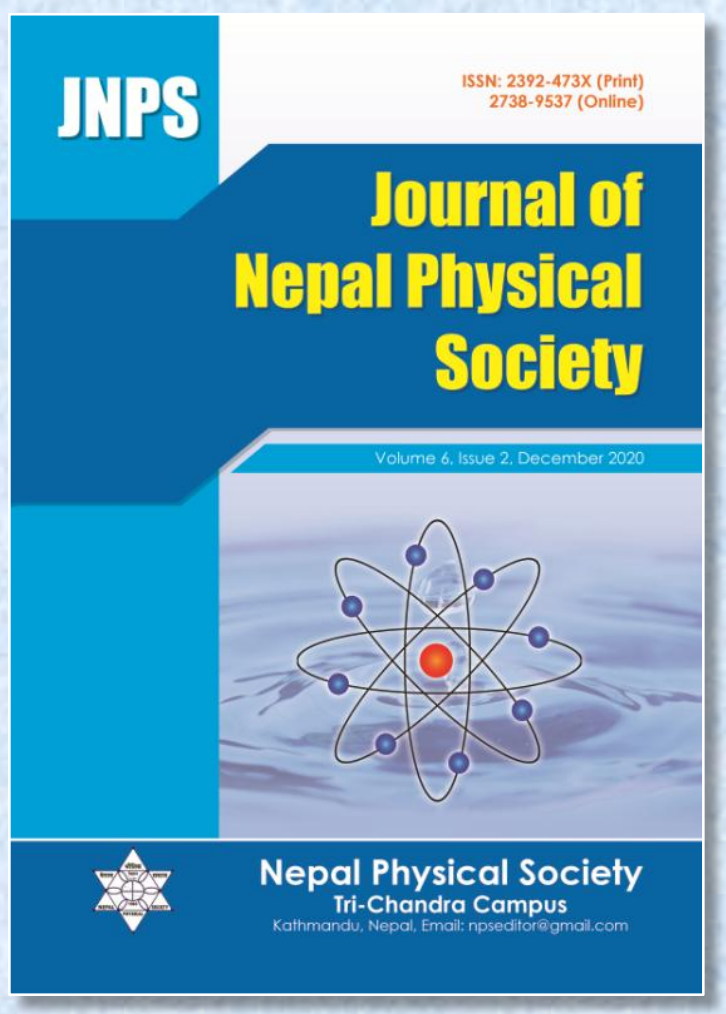

Published by:

Nepal Physical Society

P.O. Box: 2934

Tri-Chandra Campus

Kathmandu, Nepal

Email: npseditor@gmail.com 


\title{
Surface Properties of Al-Fe-Si Liquid Alloy Using Thermodynamic Database
}

\author{
U. Mehta ${ }^{1,2}$, S. K. Yadav ${ }^{2}$, I. Koirala ${ }^{1}$, D. Adhikari ${ }^{2, *}$ \\ ${ }^{1}$ Central Department of Physics, Tribhuvan University, Kirtipur, Nepal. \\ ${ }^{2}$ Department of Physics, Mahendra Morang Adarsha Multiple Campus, T. U., Biratnagar, Nepal. \\ *Corresponding Email : adksbdev@yahoo.com
}

Received: 25 October, 2020; Revised: 24 November, 2020; Accepted: 26 December, 2020

\begin{abstract}
Temperature-dependent interaction parameters for excess free energies of mixing of sub-binary systems of Al-Fe-Si ternary liquid alloys were optimised using the experiment data in the frame of Redlich-Kister (R-K) polynomials. These optimised parameters were then used to compute the partial excess free energy of sub-binary and ternary liquid alloys. The surface tension and surface concentration of sub-binary and the ternary liquid alloys were computed using Butler equation. The temperature dependent coefficients of R-K polynomials for excess surface tensions of the sub-binary systems were optimised which were then used to estimate the surface tension of ternary alloy using Chou, Kohler and Toop modelling equations at temperatures 1773, 1873, 1973 and $2073 \mathrm{~K}$. The surface tension of the ternary alloy obtained using aforementioned models were found to be in good agreement from $\mathrm{Fe}$ and $\mathrm{Al}$ corners but some deviations were observed from Si corner.
\end{abstract}

Keywords: R-K polynomials, Al-Fe-Si liquid alloy, sub-binary systems, surface tension, surface concentration.

\section{INTRODUCTION}

Iron and silicon are mostly used as common alloying ingredient in aluminium alloys to enhance the mechanical strength $[1,2]$. Al-Fe-Si system possesses high oxidation resistance and hence are mainly used for food packaging, magnetic materials for transformers, lithographic printing sheets, capacitors [2-4] and building materials [5]. The addition of iron and vanadium to the $\mathrm{Al}-\mathrm{Si}$ alloy enhances the wear resistance significantly with respect to the conventional $\mathrm{Al}-\mathrm{Si}$ alloy [6]. The Fe and $\mathrm{Si}$ atoms precipitate on solidifying the $\mathrm{Al}-\mathrm{Fe}-\mathrm{Si}$ liquid alloy and forms the hard and brittle ternary phases which enchances the mechanical properties and surface quality of the final products significantly [7]. Due to these multidisciplinary applications, many researchers [1-5, 7-12] have long been working to access the energetic of Al-Fe-Si system. The effect of cooling rate on solidification of the system was studied experimentally by Dutta and Rettenmayr [5] and they predicted that different stable and metastable compounds formed on cooling the specimen at different rates. Du et.al. [7] reported the eleven different stable complex of Al-Fe-Si in liquid and solid alloys. Lui and Chang [1] studied the thermodynamic properties and the phase equilibria of the system and reported the formation of different intermetallic compounds like $A l_{66} \mathrm{Fe}_{19} \mathrm{Si}_{5}(\mathrm{Al}, \mathrm{Si})_{10}, \mathrm{Al}_{59.8} \mathrm{Fe}_{15.2} \mathrm{Si}_{10}(\mathrm{Al}, \mathrm{Si})_{15}$, $\mathrm{Al}_{63.5} \mathrm{Fe}_{20.5} \mathrm{Si}_{16}, \mathrm{Al}_{49} \mathrm{Fe}_{16} \mathrm{Si}_{35}, \mathrm{Al}_{35} \mathrm{Fe}_{37} \mathrm{Si}_{28}$, $\mathrm{Al}_{54} \mathrm{Fe}_{26} \mathrm{Si}_{20}$ and $\mathrm{Al}_{40} \mathrm{Fe}_{25} \mathrm{Si}_{35}$. Moreover, Boulouma et al. [4] investigated the phases of $\mathrm{Al}-\mathrm{Fe}-\mathrm{Si}$ system and identified the formation of compunds like $\alpha-\mathrm{Fe}_{2} \mathrm{SiAl}_{8}, \beta-\mathrm{FeSiAl}_{8}$, $\gamma-\mathrm{FeSiAl}_{3}$ and $\delta-\mathrm{FeSi}_{3} \mathrm{Al}_{9}$. Pontevichi et al. [8] studied the phase equilibria of the system at 1000 $\mathrm{K}$ and found that the compound $\gamma-\mathrm{Al}_{3} \mathrm{FeSi}$ to be in equilibrium with the liquid containing 10.5 at.\% of $\mathrm{Si}$ and 3.2-3.5 at. \% of Fe. Novak et al. [3] 
prepared the $\mathrm{FeAl}_{20} \mathrm{Si}_{20}$ alloy by ultrahigh-energy mechanical alloying and spark plasma sintering processes and reported the anomalous compressive strength of about $1100 \mathrm{MPa}$ at room temperature which increased to $1500 \mathrm{MPa}$ at $773 \mathrm{~K}$. Moreover, they observed that the alloy of this composition showed better oxidation resistance at $1273 \mathrm{~K}$ than that of $1073 \mathrm{~K}$ due to the formation of a highly protective $\alpha-\mathrm{Al}_{2} \mathrm{O}_{3}$ layer on the surface. They further suggested that this alloy can be used as appropriate material for automobile industries and also as a material for aggressive environmental conditions. Further, several researchers had studied the surface tensions of $\mathrm{Al}-\mathrm{Fe}[13,14], \mathrm{Fe}-\mathrm{Si}[13,15$, $16]$ and $\mathrm{Si}-\mathrm{Al}[14,17]$ sub-binary liquid alloys of $\mathrm{Al}-\mathrm{Fe}-\mathrm{Si}$ system.

Therefore, the surface properties, such as surface tension and surface concentration of $\mathrm{Al}-\mathrm{Fe}-\mathrm{Si}$ ternary liquid alloy have been studied at $1773 \mathrm{~K}$, $1873 \mathrm{~K}, 1973 \mathrm{~K}$ and $2073 \mathrm{~K}$ and different cross-sections in the present work. For this purpose, the activity and excess Gibbs free energy of mixing of sub-binary systems were calculated using the optimised coefficients of $\mathrm{R}-\mathrm{K}$ polynomials for excess free energy of mixing. The surface concentration and surface tension of the binary and ternary liquid alloys were computed using Butler's equation. For the comparative study, the surface tension of the ternary alloy were also computed using Chou, Kohler and Toop models with the help of temperature-dependent optimised coefficients of $\mathrm{R}-\mathrm{K}$ polynomial for excess surface tension.

The expressions used for the computations of different physical quantities are presented in the Section 2, the results and discussion are mentioned the Section 3 and the conclusions are highlighted in the Section 4 of the work.

\section{MATHEMATICAL MODELING}

According to the Butler model, the surface tension $(\gamma)$ and the surface concentrations $\left(x^{s}\right)$ of components of binary and multi-component liquid alloys can be expressed as $[13,18-21]$

$$
\begin{aligned}
\gamma & =\gamma_{1}+\frac{R T}{\alpha_{1}} \ln \left(\frac{x_{1}^{s}}{x_{1}^{b}}\right)+\frac{G_{s, 1}^{x s}-G_{b, 1}^{x s}}{\alpha_{1}} . . \\
& =\gamma_{2}+\frac{R T}{\alpha_{2}} \ln \left(\frac{x_{2}^{s}}{x_{2}^{b}}\right)+\frac{G_{s, 2}^{x s}-G_{b, 2}^{x s}}{\alpha_{2}} . \\
& =\gamma_{3}+\frac{R T}{\alpha_{3}} \ln \left(\frac{x_{3}^{s}}{x_{3}^{b}}\right)+\frac{G_{s, 3}^{x s}-G_{b, 3}^{x s}}{\alpha_{3}} .
\end{aligned}
$$

where $\gamma_{i}(\mathrm{i}=1,2,3)$ are the surface tension, $x_{i}^{b}$ and $x_{\mathrm{i}}^{S}$ are the bulk and surface concentrations of the individual component $i$ of the alloy in their pure state and $R$ is the universal gas constant. $G_{s, i}^{x s}$ and $G_{b, i}^{x s}$ are the partial excess free energies for the surface and bulk phases of the individual component $i$ which are related as $G_{s, i}^{x s}=\beta G_{b, i}^{x s}$. The value of $\beta$ depends on the coordination number of atoms in the surface and bulk phases and its value is taken to be 0.82 [22] for the liquid metal. $\alpha_{\mathrm{i}}$ are the monolayer surface area of one mole of the pure components and its value is computed using the relation [13, 23]

$\alpha_{\mathrm{i}}=f N_{A}^{1 / 3}\left(\frac{M_{i}}{\rho_{i}}\right)^{2 / 3}$

where $f$ is called geometrical factor and its value is taken to be 1.00 [23]. The terms $N_{A}, M_{i}$ and $\rho_{i}$ are the Avogadro's number, molar mass and density of the element $i$. The partial excess Gibbs free energy $\left(G_{i}^{x S}\right)$ of component $i$ in binary and multi-component alloys are expressed in terms of integral excess Gibbs free energy of mixing $\left(G_{M}^{x S}\right)$ as $[20,24]$

$G_{i}^{x s}=G_{M}^{x s}+\sum_{j=1}^{m}\left(\delta_{i j}-x_{j}\right) \frac{\partial G_{M}^{x s}}{\partial x_{j}}$

where $\delta_{i j}$ is the Kronecker delta function defined as $\delta_{i j}=0$ for $i \neq j$ and $\delta_{i j}=1$ for $i=j$. The value of $m$ is 2 for binary and 3 for ternary liquid alloy. The excess free energy of mixing of binary liquid alloy 'ij' having bulk concentrations $x_{i}$ and $x_{j}$ are frequently expressed in terms of R-K polynomial of order 'n' as $[20,21]$

$G_{M}^{x s}=x_{i} x_{j} \sum_{k=0}^{n} \varphi_{i j}^{k}\left(x_{i}-x_{j}\right)^{k}$

where $\varphi_{i j}^{k}(k=0,1,2,3, \ldots)$ are called coefficients of R-K polynomial for excess Gibbs free energy of mixing of the binary system such that $\varphi_{j i}^{k}=$ $(-1)^{k} \varphi_{i j}^{k}$. In the present calculations, value of $\mathrm{k}$ was taken upto 2 and the higher order terms were dropped out as their contribution to the excess free energy was found to be negligible.

Following Chou [25], the expression for free energy of mixing $\left(G_{123}^{x S}\right)$ for ternary alloy can be given as 
$G_{123}^{x S}=x_{1} x_{2} \sum_{k=0}^{n} \varphi_{12}^{k}\left(x_{1}-x_{2}\right)^{k}+x_{2} x_{3} \sum_{k=0}^{n} \varphi_{23}^{k}\left(x_{2}-x_{3}\right)^{k}+x_{3} x_{1} \sum_{k=0}^{n} \varphi_{31}^{k}\left(x_{3}-x_{1}\right)^{k}+F x_{1} x_{2} x_{3}$

where $F$ is the ternary interaction term and can be given as [25]

$$
\begin{aligned}
F= & \left(2 \xi_{12}-1\right)\left[\varphi_{12}^{3}\left(3\left(x_{1}-x_{2}\right)^{2} x_{3}+3\left(x_{1}-x_{2}\right) x_{3}^{2}\left(2 \xi_{12}-1\right)+x_{3}^{3}\left(2 \xi_{12}-1\right)^{2}\right)\right. \\
& \left.+\varphi_{12}^{2}\left(\left(2 \xi_{12}-1\right) x_{3}+2\left(x_{1}-x_{2}\right)\right)+\varphi_{12}^{1}\right] \\
& +\left(2 \xi_{23}-1\right)\left[\varphi_{23}^{3}\left(3\left(x_{2}-x_{3}\right)^{2} x_{1}+3\left(x_{2}-x_{3}\right) x_{1}^{2}\left(2 \xi_{23}-1\right)+x_{1}^{3}\left(2 \xi_{23}-1\right)^{2}\right)\right. \\
& \left.+\varphi_{23}^{2}\left(\left(2 \xi_{23}-1\right) x_{1}+2\left(x_{2}-x_{3}\right)\right)+\varphi_{23}^{1}\right] \\
& +\left(2 \xi_{31}-1\right)\left[\varphi_{31}^{3}\left(3\left(x_{3}-x_{1}\right)^{2} x_{2}+3\left(x_{3}-x_{1}\right) x_{2}^{2}\left(2 \xi_{31}-1\right)+x_{2}^{3}\left(2 \xi_{31}-1\right)^{2}\right)\right. \\
& \left.+\varphi_{31}^{2}\left(\left(2 \xi_{31}-1\right) x_{2}+2\left(x_{3}-x_{1}\right)\right)+\varphi_{31}^{1}\right]
\end{aligned}
$$

The terms $x_{1}, x_{2}$ and $x_{3}$ are the mole fractions of components in the ternary alloy. The term $\xi_{i j}$ are called similarity indexes and are expressed as

$\xi_{12}=\frac{\eta_{1}}{\eta_{1}+\eta_{11}}, \quad \xi_{23}=\frac{\eta_{11}}{\eta_{11}+\eta_{111}} \quad$ and $\quad \xi_{31}=\frac{\eta_{111}}{\eta_{111}+\eta_{1}}$

The term $\eta$ are called deviation sum of squares and are computed using the relations [25]

$$
\begin{aligned}
\eta_{1}= & \int_{0}^{1}\left(G_{12}^{E}-G_{13}^{E}\right)^{2} d x_{1} \\
= & \frac{1}{30}\left(\varphi_{12}^{0}-\varphi_{13}^{0}\right)^{2}+\frac{1}{210}\left(\varphi_{12}^{1}-\varphi_{13}^{1}\right)^{2}+\frac{1}{630}\left(\varphi_{12}^{2}-\varphi_{13}^{2}\right)^{2}+\frac{1}{1386}\left(\varphi_{12}^{3}-\varphi_{13}^{3}\right)^{2} \\
& +\frac{1}{105}\left(\varphi_{12}^{0}-\varphi_{13}^{0}\right)\left(\varphi_{12}^{2}-\varphi_{13}^{2}\right)+\frac{1}{315}\left(\varphi_{12}^{1}-\varphi_{13}^{1}\right)\left(\varphi_{12}^{3}-\varphi_{13}^{3}\right) \\
\eta_{11}= & \int_{0}^{1}\left(G_{23}^{E}-G_{21}^{E}\right)^{2} d x_{2} \\
= & \frac{1}{30}\left(\varphi_{23}^{0}-\varphi_{21}^{0}\right)^{2}+\frac{1}{210}\left(\varphi_{23}^{1}-\varphi_{21}^{1}\right)^{2}+\frac{1}{630}\left(\varphi_{23}^{2}-\varphi_{21}^{2}\right)^{2}+\frac{1}{1386}\left(\varphi_{23}^{3}-\varphi_{21}^{3}\right)^{2} \\
& +\frac{1}{105}\left(\varphi_{23}^{0}-\varphi_{21}^{0}\right)\left(\varphi_{23}^{2}-\varphi_{21}^{2}\right)+\frac{1}{315}\left(\varphi_{23}^{1}-\varphi_{21}^{1}\right)\left(\varphi_{23}^{3}-\varphi_{21}^{3}\right) \\
\eta_{111}= & \int_{0}^{1}\left(G_{31}^{E}-G_{32}^{E}\right)^{2} d x_{3} \\
= & \frac{1}{30}\left(\varphi_{31}^{0}-\varphi_{32}^{0}\right)^{2}+\frac{1}{210}\left(\varphi_{31}^{1}-\varphi_{32}^{1}\right)^{2}+\frac{1}{630}\left(\varphi_{31}^{2}-\varphi_{32}^{2}\right)^{2}+\frac{1}{1386}\left(\varphi_{31}^{3}-\varphi_{32}^{3}\right)^{2}+ \\
& \frac{1}{105}\left(\varphi_{31}^{0}-\varphi_{32}^{0}\right)\left(\varphi_{31}^{2}-\varphi_{32}^{2}\right)+\frac{1}{315}\left(\varphi_{31}^{1}-\varphi_{32}^{1}\right)\left(\varphi_{31}^{3}-\varphi_{32}^{3}\right)
\end{aligned}
$$

The values of partial excess free energy of the components for the binary liquid alloys are obtained using Equation (4) in Equation (3) and putting $m=2$. Similarly, the values of partial excess free energies of the individual components in the ternary liquid alloys are obtained using Equation (5) in 
Equation (3) and putting $m=3$. The activity $\left(a_{i}\right)$ of a component $i$ can be expressed in terms of the partial excess free energy $\left(G_{i}^{x S}\right)$ at temperature $T$ using the thermodynamic relation [26]

$a_{i}=x_{i} \exp \left(\frac{G_{i}^{x S}}{R T}\right)$

The excess surface tension $\left(\sigma_{123}^{x s}\right)$ of the ternary alloy using the Chou model is obtained by using Equations (5), (6), (7) and (8) and replacing the coefficients $\varphi_{i j}^{k}$ for excess free energy by the corresponding coefficients $\left(\lambda_{i j}^{k}\right)$ for excess surface tension. Kohler model is a symmetric geometrical model and all the elements can be placed at equal footing. The expression for excess surface tension of ternary alloy on the basis of Kohler model is expressed as [20,27].

$$
\begin{aligned}
& \gamma_{123}^{x S}=\left(x_{1}^{2}+x_{2}^{2}\right) \gamma_{12}^{x S}\left(\frac{x_{1}}{x_{1}+x_{2}}, \frac{x_{2}}{x_{1}+x_{2}}\right)+\left(x_{2}^{2}+\right. \\
& \left.x_{3}^{2}\right) \gamma_{23}^{x S}\left(\frac{x_{2}}{x_{2}+x_{3}}, \frac{x_{3}}{x_{2}+x_{3}}\right)+\left(x_{3}^{2}+\right. \\
& \left.x_{1}^{2}\right) \gamma_{31}^{x S}\left(\frac{x_{3}}{x_{3}+x_{1}}, \frac{x_{1}}{x_{3}+x_{1}}\right)
\end{aligned}
$$

where $\gamma_{i j}^{x S}$ are the excess surface tension of the binary system at concentrations $\left(\frac{x_{i}}{x_{i}+x_{j}}, \frac{x_{j}}{x_{i}+x_{j}}\right)$. Toop model is an asymmetric geometrical model and a symmetric element is to be selected to apply this model. According to this model, the expression for excess surface tension of ternary alloy for a symmetrical element having bulk concentration $x_{1}$ is given by the relation $[20,28]$.

$$
\begin{aligned}
\gamma_{123}^{x s}=\frac{x_{2}}{\left(x_{2}+x_{3}\right)} & \gamma_{12}^{x s}\left(x_{1}, 1-x_{1}\right)+\left(x_{2}\right. \\
& \left.+x_{3}\right)^{2} \gamma_{23}^{x s}\left(\frac{x_{2}}{x_{2}+x_{3}}, \frac{x_{3}}{x_{2}+x_{3}}\right) \\
& +\frac{x_{3}}{\left(x_{2}+x_{3}\right)} \gamma_{13}^{x s}\left(x_{1}, 1-x_{1}\right)
\end{aligned}
$$

The surface tension $(\gamma)$ and density $(\rho)$ of a pure element at temperature $T$ are expressed in terms of its surface tension $\left(\sigma_{0}\right)$ and density $\left(\rho_{0}\right)$ near melting temperature $T_{0}$ using the linear relations [29]

$$
\begin{aligned}
& \gamma=\gamma_{0}+\frac{\partial \gamma}{\partial T}\left(T-T_{0}\right), \\
& \text { and } \quad \rho=\rho_{0}+\frac{\partial \rho}{\partial T}\left(T-T_{0}\right)
\end{aligned}
$$

where $\partial \gamma / \partial T$ and $\partial \rho / \partial T$ are the temperature derivatives terms of surface tension and density respectively.

The excess surface tension $\left(\gamma^{x s}\right)$ of the liquid alloy is the deviation between surface tension and its ideal value and is given as

$\gamma^{x s}=\gamma-\gamma^{\text {ideal }}=\gamma-\sum_{i}\left(x_{i} \gamma_{i}\right)$

where $\gamma_{i}$ are the surface tension of the pure elements at working temperature.

\section{RESULTS AND DISCUSSION}

The coefficients of R-K polynomials for the integral excess Gibbs free energy of mixing $\left(G_{M}^{x S}\right)$ for the sub-binary systems (Al-Fe, $\mathrm{Fe}-\mathrm{Si}$ and $\mathrm{Si}-\mathrm{Al}$ ) were optimised using the experimental values $[30,31]$ of the enthalpy of mixing and excess entropy of mixing and are listed in Table 1. These optimised parameters were then used in Equation (4) to compute $G_{M}^{x s}$ of the sub-binary systems. The computed values of the present work were found to be in excellent agreement with the experimental values (Figures 1(a-c)). Moreover, the computed values of $G_{M}^{x S}$ for Al-Fe system was found to be excellent agreement with the work of Adhikari et. al. [32] and Yadav et. al. [33], and that of Al-Si with the work of Adhikari et al. [34]. But the values obtained using the parameters given in Cost 507 [35] and the results of Kostov et al. [36] (for Al-Fe system) were found to deviate from the experimental results. Therefore, the optimised parameters of the present work were considered for further computations. Moreover, the perusal of Figures 1(a-c) correspond that $\mathrm{Fe}-\mathrm{Si}$ is strongly interacting, $\mathrm{Al}-\mathrm{Fe}$ is moderately interacting and $\mathrm{Si}-\mathrm{Al}$ is weakly interacting in nature. 

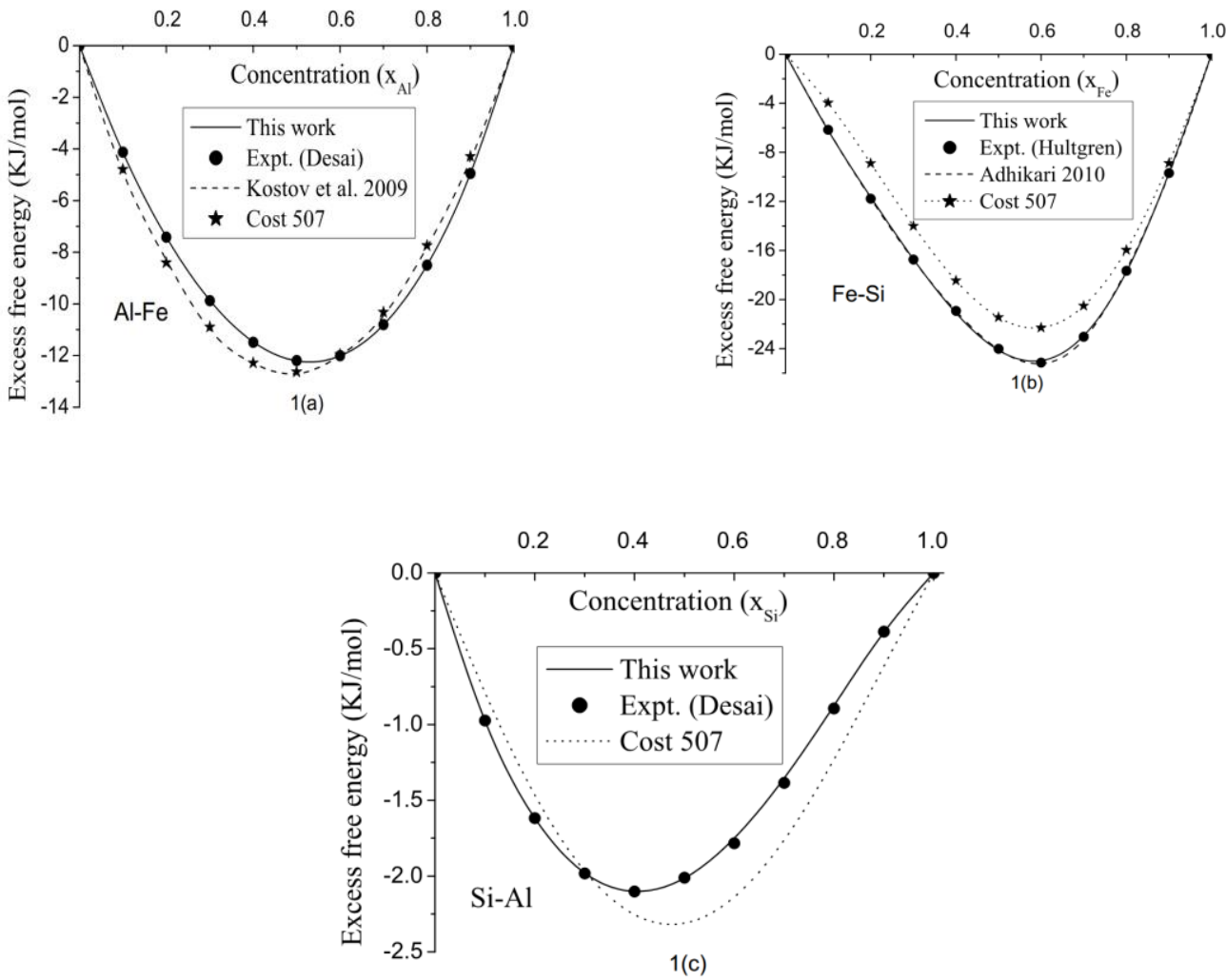

Fig. 1: Variation of excess free energy of mixing for sub-binary systems of Al-Fe-Si ternary liquid alloy with bulk concentration. (a) Al-Fe at $1873 \mathrm{~K}$, (b) Fe-Si at $1873 \mathrm{~K}$ and (c) Si-Al at $1700 \mathrm{~K}$.

Table 1: Optimised coefficients of R-K polynomial for excess free energy of mixing for the sub-binary systems of liquid Al-Fe-Si alloy (this work).

\begin{tabular}{|l|l|}
\hline Sub-binary system & Optimised parameters $\left(\varphi^{k}\right)\left[\mathrm{Jmol}^{-1}\right]$ \\
\hline Al-Fe & $\varphi^{0}=-78925+16.068 T, \varphi^{1}=-16314+5.681 T$ \\
& $\varphi^{2}=-1766-0.380 T$ \\
\hline Fe-Si & $\varphi^{0}=-151490+29.357 T, \varphi^{1}=-37170-2.290 T$ \\
& $\varphi^{2}=36570-12.6060 T, \varphi^{3}=29560-1.374 T$ \\
\hline Si-Al & $\varphi^{0}=-11263+1.890 T, \varphi^{1}=4423-0.479 T$ \\
& $\varphi^{2}=1790-0.627 T, \varphi^{3}=-1565+1.330 T$ \\
\hline
\end{tabular}

The activity is an important thermodynamic function of the liquid alloys. The optimised parameters for the excess Gibbs free energy of mixing are considered to be acceptable only when they well reproduces activity. The activities of the constituent atoms of the sub-binary systems were calculated using Equations (3), (4) and (9) with help of parameters of Table 1 . The compositional dependence of the activities of the monomers of the sub-binary systems are presented in Figure 2 (a-c). The computed values of activities of $\mathrm{Al}\left(a_{A l}\right)$ and $\mathrm{Fe}$
$\left(a_{F e}\right)$ of Al-Fe liquid alloy at $1873 \mathrm{~K}$ were found to be in good agreement with the respective experimental [30] and literature [32, 33, 36] values (Figure 2(a)). Likewise, the computed values of activities of the components of Fe-Si alloy at 1873 $\mathrm{K}$ agree with the experimental data [31] and with the work of Adhikari et al. [34] but some considerable deviations were depicted for the activity of $\mathrm{Si}$ in concentration range $0.15<x_{\mathrm{Fe}}<0.4$ (Figure 2(b)). The computed values of activities of $\mathrm{Si}\left(a_{S i}\right)$ and $\mathrm{Al}\left(a_{A l}\right)$ of $\mathrm{Si}-\mathrm{Al}$ alloys at $1700 \mathrm{~K}$ were in good 
agreement with the experimental [30] data and the values computed using the parameters from Cost 507 [35] (Figure 2(c)). As the optimised parameters for the excess Gibbs free energy of mixing have well reproduced the activity of the preferred systems, these parameters were considered for further computations of the surface properties.
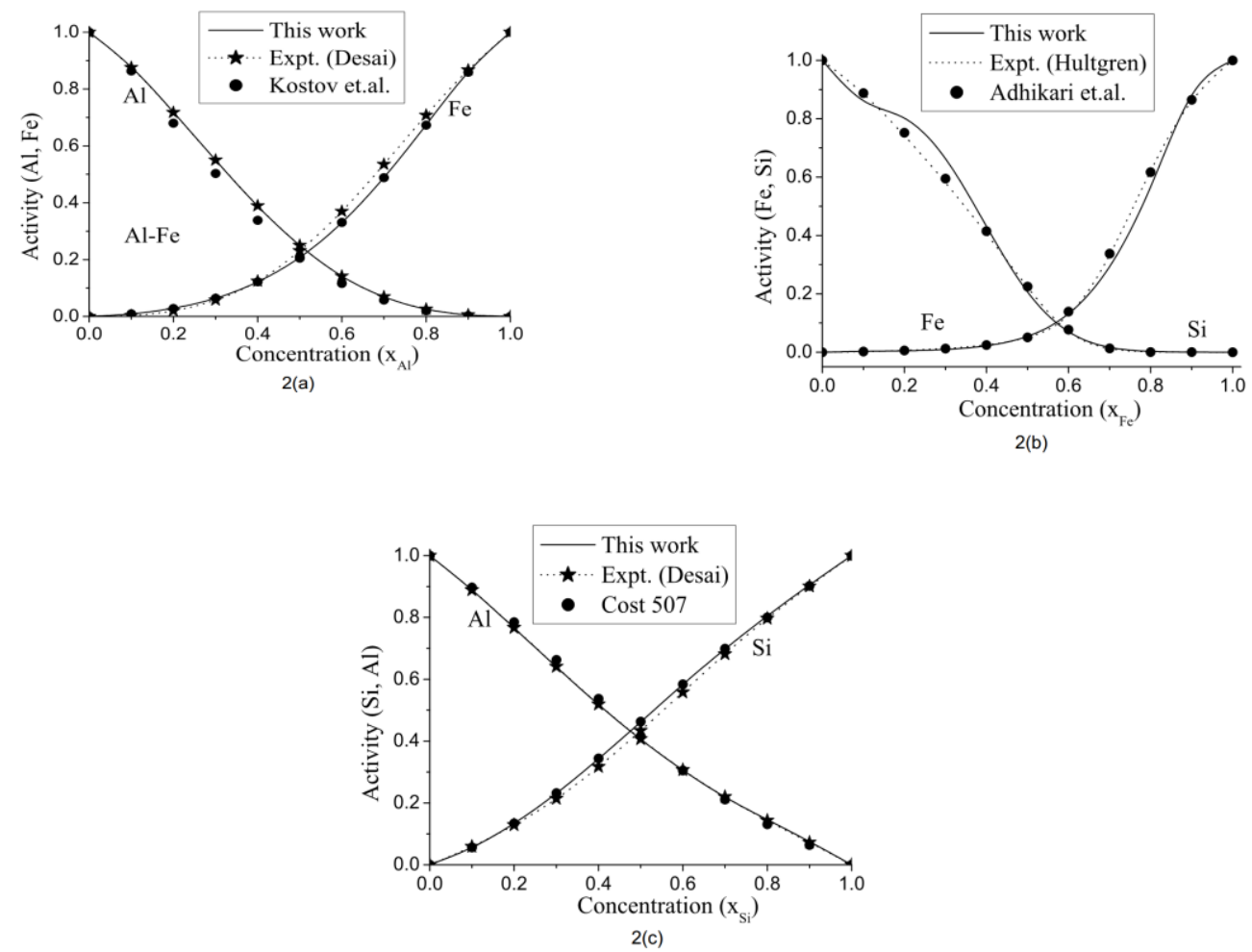

Fig. 2: Variation of activities of the components of the sub-binary systems of liquid Al-Fe-Si ternary alloy with bulk concentration. (a) Al-Fe at 1873 K, (b) Fe-Si at $1873 \mathrm{~K}$ and (c) Si-Al at $1700 \mathrm{~K}$.

The surface tensions and densities of the pure elements of the sub-binary systems were calculated at working temperatures using Equation (12) and the data presented in Table 2. The surface tensions of the sub-binary liquid alloys were then computed using Equations (1) and (2) and are plotted in Figure 3. The computed values of the surface tensions for $\mathrm{Al}-\mathrm{Fe}$ and $\mathrm{Fe}-\mathrm{Si}$ systems at $1823 \mathrm{~K}$ were compared with the work of Tanaka and Lida [13]. There appeared some deviations between these results and these deviations might be due to the difference in the values of input parameters, such as $f$ and $\beta$. In present computations, $f=1.00$ and $\beta=0.82[33,37,38]$ were taken but Tanaka and Lida carried out the work taking $f=1.091$ and $\beta=0.75$. Additionally, the result of this work for the surface tension of Si-Al system at $1773 \mathrm{~K}$ was found to be in agreement with the results of Kobatake et al. [17] at higher bulk concentration of $\mathrm{Si}$.

Table 2: Density $\left(\rho_{0}\right)$ and surface tension $\left(\sigma_{0}\right)$ of elements near their melting temperature $\left(T_{0}\right)$ and their derivatives w.r.t. temperature [28].

\begin{tabular}{|l|l|l|l|l|l|}
\hline Elements & $\begin{array}{c}\boldsymbol{T}_{\mathbf{0}} \\
(\mathbf{K})\end{array}$ & $\begin{array}{c}\boldsymbol{\rho}_{\mathbf{0}} \\
\left(\mathbf{k g ~ m}^{-\mathbf{3}}\right)\end{array}$ & $\begin{array}{c}\boldsymbol{1} \boldsymbol{\partial \rho / \partial T} \\
\left(\mathbf{k g ~ m}^{-\mathbf{3}} \mathbf{K}^{-\mathbf{1}}\right)\end{array}$ & $\begin{array}{c}\boldsymbol{\sigma}_{\mathbf{0}} \\
\left(\mathbf{N m}^{-\mathbf{1}}\right)\end{array}$ & $\begin{array}{c}\boldsymbol{\partial \sigma} / \boldsymbol{\partial T} \\
\left(\mathbf{N m}^{-\mathbf{1}} \mathbf{K}^{-\mathbf{1}}\right)\end{array}$ \\
\hline $\mathrm{Al}$ & 933 & 2385 & -0.35 & 0.914 & -0.00035 \\
\hline $\mathrm{Fe}$ & 1809 & 7030 & -0.88 & 1.872 & -0.00049 \\
\hline $\mathrm{Si}$ & 1683 & 2530 & -0.35 & 0.865 & -0.00013 \\
\hline
\end{tabular}




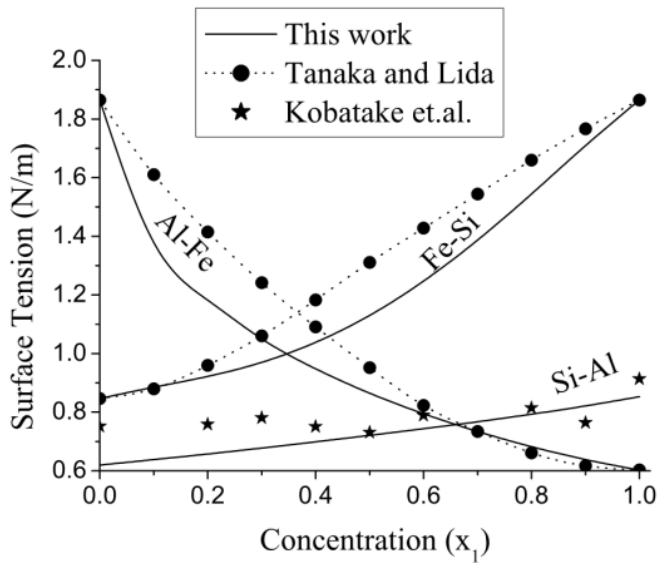

Fig. 3: Variation of surface tensions of sub-binary alloys of Al-Fe-Si ternary system with the bulk concentration.

The Butler equation was used to estimate the surface concentrations of components of the ternary liquid alloy at cross-sections $x_{F e} / x_{S i}=5: 5$ from $\mathrm{Al}$ corner, $x_{S i} / x_{A l}=5: 5$ from $\mathrm{Fe}$ corner and $x_{A l} / x_{F e}=5: 5$ from Si corner. For this purpose, the input parameters from Tables 1 and 2 were used in Equations (1), (2) and (12). The variation of the surface concentration with the bulk concentration of the system at $1773 \mathrm{~K}$ are presented in Figures 4 (a-c). The surface concentration of each component in the alloy was found to increase with the rise of the respective bulk concentration. But some unusual trend had been depicted at $x_{S i} / x_{A l}=5: 5$ from $\mathrm{Fe}$ corner in which the surface concentration of $\mathrm{Al}$ increases with the decrease in its bulk concentration upto $\mathrm{x}_{\mathrm{Fe}} \leq 0.6$ (Figure 4(b)). This might be because when the bulk concentration of $\mathrm{Fe}$ is gradually increased, Si atoms tend to make complexes with the $\mathrm{Fe}$ atoms as $\mathrm{Fe}-\mathrm{Si}$ system is found to be strongly interacting in nature than that of $\mathrm{Al}-\mathrm{Fe}$ system due to which $\mathrm{Al}$ atoms tend to segregate on the surface phase. At equiatomic bulk concentration of components in ternary alloy, the extent of surface segregation of $\mathrm{Al}$ atoms is much higher than that of $\mathrm{Si}$ atoms while $\mathrm{Fe}$ atoms is less than that of $\mathrm{Si}$ (Figures 4 (a-c)). These observations reveal that the component having lower value of surface tension has the greater surface segregation. The surface concentration of $\mathrm{Si}$ and $\mathrm{Al}$ were found to decrease and that of $\mathrm{Fe}$ was found to increase gradually with the rise in temperature of the system at bulk concentration $\mathrm{Si}_{33} \mathrm{Al}_{33} \mathrm{Fe}_{34}$ (Figure 4(d)).
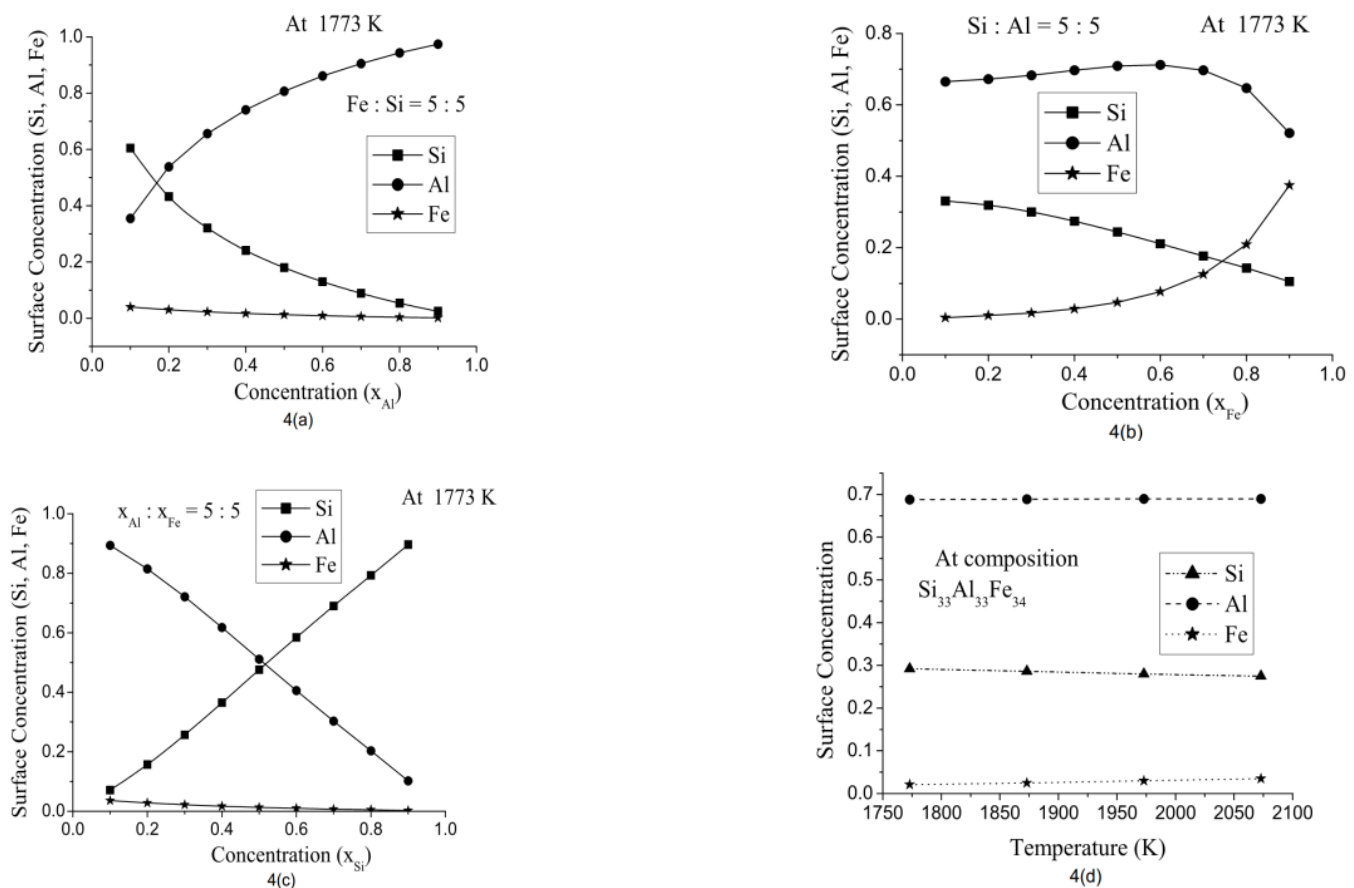

Fig. 4: Variation of surface concentration of the components of the Al-Fe-Si ternary liquid alloy with concentration. (a) at $x_{F e} / x_{S i}=5: 5$ from Al corner, (b) at $x_{S i} / x_{A l}=5: 5$ from Fe corner, (c) at $x_{A l} / x_{F e}=5: 5$ from Si corner and (d) Variation of surface concentration of the Al-Fe-Si ternary liquid alloy with temperatures at a fixed concentration

$$
\mathrm{Si}_{33} \mathrm{Al}_{33} \mathrm{Fe}_{34} \text {. }
$$


Table 3: Optimised coefficients of R-K polynomial for excess surface tension of sub-binary systems of Al-Fe-Si alloy (this work).

\begin{tabular}{|l|l|}
\hline Sub-binary system & Optimised parameters $\left(\lambda^{k}\right)\left[\mathrm{Nm}^{-1}\right]$ \\
\hline Al-Fe & $\lambda^{0}=-2.099+3.693 \times 10^{-4} T, \lambda^{1}=1.549-3.355 \times 10^{-4} T$ \\
& $\lambda^{2}=-3.540+1.098 \times 10^{-3} T, \lambda^{3}=3.350-1.106 \times 10^{-3} T$ \\
\hline Fe-Si & $\lambda^{0}=-2.263+7.437 \times 10^{-4} T, \lambda^{1}=-0.522+3.150 \times 10^{-4} T$ \\
& $\lambda^{2}=-1.195+1.582 \times 10^{-3} T-3.905 \times 10^{-7} T^{2}$ \\
& $\lambda^{3}=-1.207+1.202 \times 10^{-3} T-2.909 \times 10^{-7} T^{2}$ \\
\hline Si-Al & $\lambda^{0}=0.205-1.515 \times 10^{-4} T, \lambda^{1}=0.074-5.191 \times 10^{-5} T$ \\
& $\lambda^{2}=0.0172-2.095 \times 10^{-5} T, \lambda^{3}=0.0145-1.487 \times 10^{-5} T$ \\
\hline
\end{tabular}

The excess surface tensions of the sub-binary liquid alloys were computed using Equation (13). These values were then used to optimise the coefficients of R-K polynomial for excess surface tension and are presented in Table 3. The surface tension of the liquid Al-Fe-Si ternary alloy at different temperatures and concentrations were then calculated using Butler (Equation (1)), Chou (Equations (5-8)), Kohler (Equation (10)) and Toop (Equation (11)) models at above mentioned cross-sections and corners. The compositional and the temperature dependence of the surface tension of the ternary system are shown in Figures 5(a-d).
The surface tension of the ternary alloy was found to increase with the rise in concentration of $\mathrm{Fe}$ (Figure 5(b)) and decrease with the rise in the concentration of $\mathrm{Al}$ (Figure 5(a)). This might be due to the greatest value of the surface tension of $\mathrm{Fe}$ and the least for $\mathrm{Al}$ among the constituents of the system at $1773 \mathrm{~K}$. As the surface tension of $\mathrm{Si}$ lies in between $\mathrm{Al}$ and $\mathrm{Fe}$, the variation of the surface tension of the system from Si corner is the least (Figure 5(c)). The surface tension of the system was found to decrease linearly with the increase in its temperature at all ternary concentrations (Figure 5(d)).

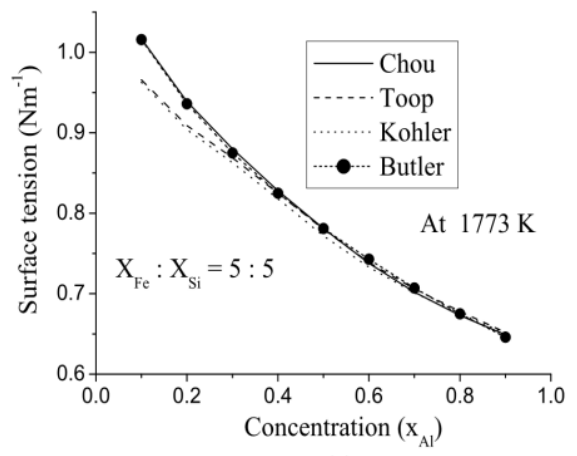

5(a)

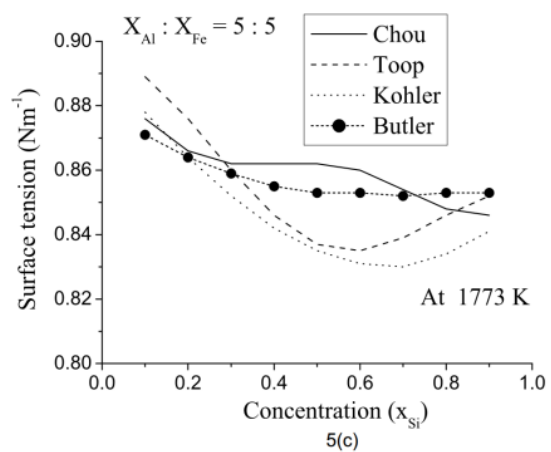

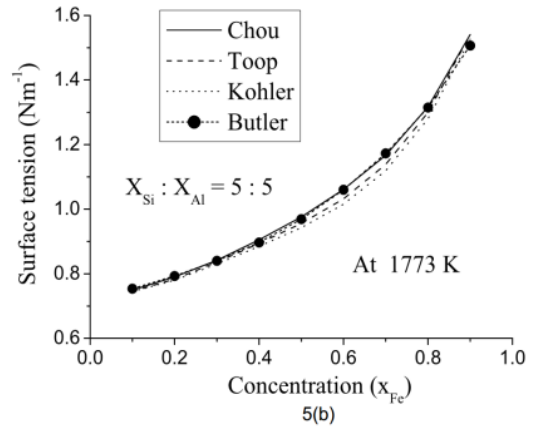

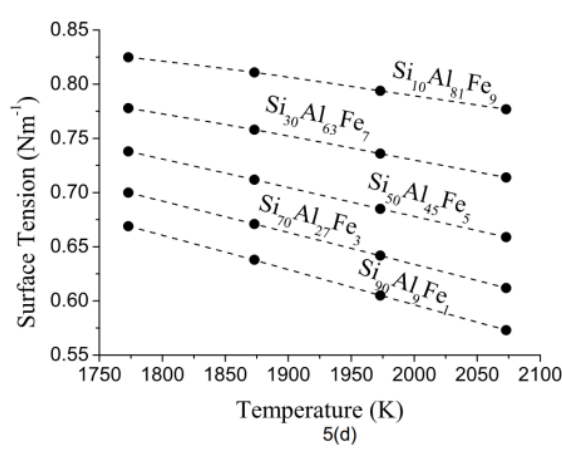

Fig. 5: Variation of surface tension of the liquid Al-Fe-Si ternary alloy with concentration. (a) at $x_{F e} / x_{S i}=5: 5$ from Al corner, (b) at $x_{S i} / x_{A l}=5: 5$ from Fe corner, (c) at $x_{A l} / x_{F e}=5: 5$ from Si corner and (d) Variation of surface tension of the liquid Al-Fe-Si ternary alloy with temperatures at five different fixed concentrations. 


\section{CONCLUSIONS}

The computed and the experimental values of the excess Gibbs free energy of mixing and the activity of the sub-binary systems of the liquid $\mathrm{Al}-\mathrm{Fe}-\mathrm{Si}$ alloy were found to be in good agreement which provided the validity of the optimised parameters of this work. Among the three sub-binary systems, $\mathrm{Fe}-\mathrm{Si}$ was found to be strongly interacting, $\mathrm{Al}-\mathrm{Fe}$ was found to be moderately interacting and $\mathrm{Si}-\mathrm{Al}$ was found to be weakly interacting. Surface concentrations of the components of the ternary system were found to increase with the rise in the respective bulk concentrations. The component having lower values of the surface tension segregates more on the surface phase of the initial melt. The surface tension of the ternary system was found to increase with the increase in Fe content and decrease with the increase in $\mathrm{Al}$ content. Moreover, the surface tension of the ternary alloy was found to decrease linearly with the rise in temperature.

\section{REFERENCES}

[1] Liu, Z. K. and Chang Y. A. Thermodynamic assessment of the Al-Fe-Si system. Metallurgical and Materials Transactions $\AA$, 30(4): 1081-1095 (1999).

[2] Ghosh, G. Aluminium-Iron-Silicon. In Iron Systems, Part 1, 184-266 (2008).

[3] Novak, P.; Vanka, T.; Nova, K.; Stoulil, J.; Prusa, F.; Kopecek, J.; Hausild, P. and Laufek, F. Structure and properties of $\mathrm{Fe}-\mathrm{Al}-\mathrm{Si}$ alloy prepared by mechanical alloying. Materials, 12(15): 2463 (2019).

[4] Boulouma, A.; Drici, A.; Benaldjia, A.; Guerioune, M. and Vrel, D. The formation of $\left(\mathrm{Al}_{8} \mathrm{Fe}_{2} \mathrm{Si}, \mathrm{Al}_{13} \mathrm{Fe}_{4}\right)$ phases from $\mathrm{Al}-\mathrm{Fe}-\mathrm{Si}$ system by TE mode. In AIP Conference Proceedings. 1653(1): 020023. AIP Publishing LLC (2015).

[5] Dutta, B. and Rettenmayr, M. Effect of cooling rate on the solidification behaviour of $\mathrm{Al}-\mathrm{Fe}-\mathrm{Si}$ alloys. Materials Science and Engineering: A, 283: 218-224 (2000).

[6] Koraman, E.; Baydogan, M.; Sayilgan, S. and Kalkanli, A. Dry sliding wear behavior of $\mathrm{Al}-\mathrm{Fe}-\mathrm{Si}-\mathrm{V}$ alloys at elevated temperatures. Wear, 322: 101-107 (2015).

[7] Du, Y.; Schuster, J. C.; Liu, Z. K.; Hu, R.; Nash, P.; Sun, W.; Zhang, W.; Wang, J.; Zhang, L.; Tang, C. and Zhu, Z. A thermodynamic description of the Al-Fe-Si system over the whole composition and temperature ranges via a hybrid approach of Calphad and key experiments. Intermetallics, 16(4): 554-570 (2008).
[8] Pontevichi, S.; Bosselet, F.; Barbeau, F.; Peronnet, M. and Viala, J.C. Solid-liquid phase equilibria in the Al-Fe-Si system at $727^{\circ} \mathrm{C}$. Journal of Phase Equilibria and Diffusion, 25(6): 528-537 (2004).

[9] Raghavan, V. Al-Fe-Si (aluminum-iron-silicon). Journal of Phase Equilibria and Diffusion, 30(2): 184-188 (2009).

[10] Zakharov, A. M.; Guldin, I. T.; Arnold, A. A. and Matsenko, Y. A. Phase equilibria in multi-component aluminum systems with copper, iron, silicon, manganese and titanium. Metalloved. Obrab. Tsv. Splavov, RAN. Inst. Metallurgii. M, 6-17, (1992).

[11] Anglezio, J. C.; Servant, C. and Ansara, I. Contribution to the experimental and thermodynamic assessment of the $\mathrm{Al}-\mathrm{Ca}-\mathrm{Fe}-\mathrm{Si}$ system-I. Al-Ca-Fe, Al-Ca-Si, Al- $\mathrm{Fe}-\mathrm{Si}$ and $\mathrm{Ca}-\mathrm{Fe}-\mathrm{Si}$ systems. Calphad, 18(3): 273-309 (1994).

[12] Griger, A. and Stefaniay, V. Equilibrium and non-equilibrium intermetallic phases in Al-

$\mathrm{Fe}$ and Al-Fe-Si alloys. Journal of Materials Science, 31(24): 6645-6652 (1996).

[13] Tanaka, T. and Iida T. Application of a thermodynamic database to the calculation of surface tension for iron-base liquid alloys. Journal of Iron Steel Research International, 65(1): 21-28 (1994).

[14] Bainbridge, I. F. and Taylor, J. A. The surface tension of pure aluminum and aluminum alloys. Metallurgical and Materials Transactions A, 44(8): 3901-3909 (2013).

[15] Dzhemilev, N. K.; Popel, S. I. and Tsarevskii, B. $\mathrm{V}$. Isotherm of the density and surface tension of iron-silicon melts. Fiz. Met. Metalloved, 18(1): 83-87 (1964).

[16] Kawai, Y.; Mori, K.; Kishimoto, M.; Ishikura, K. and Shimada, T. Surface tension of liquid $\mathrm{Fe}-\mathrm{C}-\mathrm{Si}$ alloys. Tetsu-to-Hagané, 60(1): 29-37 (1974).

[17] Kobatake, H.; Brillo, J.; Schmitz, J. and Pichon, P. $\mathrm{Y}$. Surface tension of binary $\mathrm{Al}-\mathrm{Si}$ liquid alloys. Journal of Materials Science, 50(9): 3351-3360 (2015).

[18] Butler, J. A. V. The thermodynamics of the surfaces of solutions. Proceedings of the Royal. Society of London-A., 135(827): 348-375 (1932).

[19] Yeum, K. S.; Speiser, R. and Poirier, D. R. Estimation of the surface tensions of binary liquid alloys. Metallurgical Transactions B, 20(5): 693-703 (1989).

[20] Yan, L.; Zheng, S.; Ding, G.; Xu, G. and Qiao Z. Surface tension calculation of the $\mathrm{Sn}-\mathrm{Ga}-\mathrm{In}$ ternary alloy. Calphad, 31(1): 112-119 (2007).

[21] Fima, P. and Novakovic, R. Surface tension 
modelling of liquid $\mathrm{Cd}-\mathrm{Sn}-\mathrm{Zn}$ alloys. Philosophical Magazine, 6435: 1-17 (2018).

[22] Kaptay, G. A method to calculate equilibrium surface phase transition lines in monotectic systems. Calphad, 29(1): 56-67 (2005).

[23] Mekler, C. and Kaptay, G. Calculation of surface tension and surface phase transition line in binary $\mathrm{Ga}-\mathrm{Tl}$ system. Material Science and Engineering A, 495(1-2): 65-69 (2008).

[24] Egry, I.; Holland-Moritz, D.; Novakovic, R.; Ricci, E.; Wunderlich, R. and Sobczak, N. Thermo-physical properties of liquid AlTi-based alloys. Interntional Journal of Thermophysics, 1: 949-965 (2010).

[25] Chou, K. C.; Li, W. C.; Li, F. and He, M. Formalism of new ternary model expressed in terms of binary regular-solution type parameters. Calphad, 20(4): 395-406, (1996).

[26] Marjanović, S.; ManaSijević, D.; Živković, D.; Gusković, D. and Minić, D. Calculatio of thermodynamic properties for ternary $\mathrm{Ag}-\mathrm{Cu}-\mathrm{Sn}$ system. RMZ-Materials and Geoenvironment, 56(1): 30-37 (2009).

[27] Kohler, F. Zur berechnung der thermodynamischen daten eines ternären systems aus den zuge-hörigen binären systemen. Monatshefte für Chemie und verwandte Teile anderer Wissenschaften, 91(4): 738-740 (1960).

[28] Toop G. W. Predicting ternary activities using binary data. Trans. TMS-AIME, 223: 850-855(1965).

[29] Gale, W. F. and Terry, C. Smithells Metals Reference Book. Elsevier (2003).

[30] Desai, P. D. Thermodynamic properties of selected binary aluminum alloy systems. Journal of Physical and Chemical Reference Data, 16(1): 109-124 (1987).
[31] Hultgren, R.; Desai, P. D.; Hawkins, D. T. Molly Gleiser, and Kelley, K. K. Selected values of the thermodynamic properties of binary alloys. Technical Report, National Standard Reference Data System (1973).

[32] Adhikari, D.; Yadav, S. K.; Jha, L. N. Thermo-physical properties of $\mathrm{Al}-\mathrm{Fe}$ melt. Journal of the Chinese Advanced Materials Society, 2(3): 149-158 (2014).

[33] Yadav, S. K.; Jha, L. N. and Adhikari, D. Modeling equations to predict the mixing behaviour of $\mathrm{Al}-\mathrm{Fe}$ liquid alloy at different temperatures. Bibechana, 15: 60-69 (2018).

[34] Adhikari, D.; Jha, I. S. and Singh, B. P. Structural asymmetry in liquid $\mathrm{Fe}-\mathrm{Si}$ alloys. Philosophical Magazine, 90(20): 2687-2694 (2010).

[35] Ansara, I., Dinsdale, A. T. and Rand, M. H. Thermochemical Database for Light Metal Alloys (Cost507), (1998).

[36] Kostov, A.; Friedrich, B. and Živković, D. Thermodynamic calculations in alloys $\mathrm{Ti}-\mathrm{Al}$, $\mathrm{Ti}-\mathrm{Fe}, \mathrm{Al}-\mathrm{Fe}$ and Ti-Al-Fe. Journal of Mining and Metallurgy, 44B: 49-61 (2008).

[37] Mehta, U., Koirala, I., Yadav, S. K., Koirala, R. P. and Adhikari, D. Prediction of thermodynamic and surface properties of ternary $\mathrm{Ti}-\mathrm{Si}-\mathrm{Fe}$ liquid alloy. Modelling and Simulation in Materials Science and Engineering, 28(6): 065010 (2020).

[38] Mehta, U.; Yadav, S. K.; Koirala, I.; Koirala, R. P.; Shrestha, G. K. and Adhikari, D. Study of surface tension and viscosity of $\mathrm{Cu}-\mathrm{Fe}-\mathrm{Si}$ ternary alloy using a thermodynamic approach. Heliyon, 6(8): e04674 (2020). 